\title{
Reflections on different labels for Factor V
}

\author{
FRITZ OSTENDORF* $\ddagger$ and ALOIS ANGLEITNER $\ddagger$ \\ *University of Koblenz-Landau, Germany \\ †University of Bielefeld, Germany
}

\begin{abstract}
Discrepancies among different versions of Factor $V$ may be largely explained by differences in the personality definitions and the variable selections used in various national trait taxonomies. Like any other social category the fifth factor has fuzzy boundaries and its meaning depends on the number and prototypicality of the exemplars included in the category. Resulting from taxonomies of traits (Norman, 1967; Goldberg, 1990) or dispositions (Ostendorf, 1990) the Five-Factor Model is not intended to represent or capable of representing the structure of all individual differences (e.g. attitudes, physical characteristics). Clear Intellect and Imagination versions of Factor $V$ have only resulted from taxonomies including abilities and talents in their trait definition. The meaning of at least three of the Big Five would probably change if values - which we view as action prescriptions or behavioural intentions - were regarded as dispositions. Intellect, Imagination, and Creativity are the most prototypical attributes belonging to the core of Factor $V$. Comparisons among the various personality definitions and the procedures currently used in trait taxonomic research are needed to examine their effects on the replicability and the meaning of Factor $V$.
\end{abstract}

\section{INTRODUCTION}

Evidence in support of the fifth factor in the Big-Five model of personality has been provided by findings from adjective studies as well as large-scale questionnaire studies (Ostendorf and Angleitner, 1992). However, the interpretation of this fifth factor remains a controversial issue, as the contributions to this Special Issue illustrate. We will concentrate our remarks on three main questions: (i) is labelling the fifth factor as 'intellect' instead of another label the result of biased selections of variables?; (ii) how should we view the relations between dispositions, attitudes, and values?; and (iii) what is the core of the fifth factor?

$\ddagger$ Correspondence should be addressed to: Fritz Ostendorf, University of Koblenz-Landau, Department of Psychology, Im Fort 7, 76829 Landau, Germany or Alois Angleitner, University of Bielefeld, Department of Psychology, Universitätsstrasse 25, 33615 Bielefeld, Germany. 


\section{THE FIFTH FACTOR AS INTELLECT}

The clearest discrepancies across findings from various taxonomies concern Factor V. However, this factor has emerged in very similar forms in both American and German taxonomies, and according to results reported by Goldberg (1990), Ostendorf (1990), Angleitner and Ostendorf (1992), and Ostendorf and Angleitner (1993), Intellect and Imagination are probably the most correct labels for the core meaning of this personality dimension. In contrast to the replicated American-German version of Factor V, studies of the Dutch personality language have resulted in an extraverted $(\mathrm{V}+\mathrm{I}+)$ version of the fifth factor defined by adjectives such as critical, sharp, and militant (De Raad, 1992; Hofstee, De Raad, Kiers, Ostendorf and Goldberg, 1992).

Furthermore, Intellect or Imagination did not emerge clearly in taxonomies of the Hungarian and Italian lexica. In a study by Szirmák and De Raad (1994) the markers for Factor V published by Goldberg (1992) had no matches in the fifth factor of the Hungarian language. The Hungarian Factor V, called Integrity, was conceptually closest to Agreeableness (Szirmák and De Raad, 1994, p. 112). However, at least 14 presumed Factor-V markers were identified in the sample of 561 adjectives analysed in the Hungarian study. But, these markers loaded mostly on the Hungarian factors Extraversion and Emotional Stability.

Interestingly, the Italian Factor $\mathrm{V}$ seems to be closely related to the meaning of the Dutch Factor V (Caprara and Perugini, 1994). Similar adjectives, selected from the 10-12 marker variables of the fifth factor reported in both national studies (De Raad, 1992; Caprara and Perugini, 1994), were, for example, critical (critical), sharp (sharp), militant (rebellious) versus prudish (puritan), cringing (servile), and characterless (obedient). ${ }^{1}$ However, in contrast to the Dutch $\mathrm{V}+\mathrm{I}+$ version of Factor V, the fifth Italian factor was found to be a blend of Openness and Agreeableness $(\mathrm{V}+\mathrm{II}+)$; the latter constructs were measured by factor scores derived from a common-factor analysis of the NEO-Personality-Inventory scales (Costa and McCrae, 1985) and the scales of the Big-Five Questionnaire (BFQ, Caprara, Barbaranelli, Borgogni and Perugini, 1993).

Unlike De Raad (1994), we believe that the differences between the various national versions of Factor $\mathrm{V}$ are less the result of procedural variations in the compilation of the master pool (in fact, the Dutch selection rules were adopted for the German taxonomy), but more due to possible differences in dictionaries. Above all, however, we believe-and this is in agreement with De Raad-that different Factor V versions come about because of differences in the definition of personality used to select trait terms after the master pool has been compiled.

The American and the German taxonomies are very similar both in their personality definition and in their findings, whereas the Dutch, Hungarian, and Italian taxonomies also form a separate, closely interrelated group. Roughly speaking, the main difference lies in the use of a narrower versus a broader trait or personality definition to select terms from the lexicon. That is, the Five-Factor Model (FFM) replicated in the German language is based on a representative selection of prototypical terms referring to dispositions (temperament, character, and ability) that were distinguished from other fundamental aspects of personality such as world views, beliefs, brief internal reactions (such as emotions and cognitions), permanent physical features,

${ }^{1}$ Italian marker adjectives in parentheses. 
and pure evaluations (Angleitner, Ostendorf and John, 1990; Ostendorf, 1990). In other words, the German Big-Five factors may be regarded as a structural model of psychological dispositions. The set of personality-descriptive categories constituting the implicit personality definition used in both Goldberg's and in the German taxonomy were selected largely from the same roots. For example, like Goldberg, we adapted the distinction between traits, temporary states, and activities from Allport and Odbert (1936) and Norman (1967). Goldberg (1990) constructed his Big-Five taxonomy largely on Norman's (1967) category of 'biophysical traits', and the German team separated dispositions from states, activities, roles, relationships, physical, pure evaluative terms, and other categories of personality characteristics, most of which had already been introduced by Norman (1967). Although it is unclear to us whether the correct American translation of the German term 'disposition' is 'biophysical trait' or simply 'trait', the American and the German Big-Five factors are most probably based on very similar selections of personality-descriptive terms.

In contrast, the Dutch, Italian, and Hungarian teams used more 'permeable' sieves to select representative sets of personality descriptors from their languages. Hence, they used a broader definition of personality than that of the category of Dispositions in the German taxonomy. For example, in the Italian taxonomy, adjectives were selected mainly according to a single utility criterion according to which a group of judges were introduced to answer two questions simultaneously: does the adjective fit into the sentence ' $X$ is an [adjective] person'? and 'How useful is this adjective for describing personality'? (Caprara and Perugini, 1994). Szirmák and De Raad (1994) used the familiarity and personality-relevance ratings of judges, and only secondarily a trait - state - other categorization of the adjectives as criteria for the selection of a representative set of personality descriptive terms. Finally, the Dutch selection was essentially guided by three criteria, called the nature, the person, and the fundamentality criteria (Brokken, 1978; De Raad, 1992). ${ }^{2}$ There is no empirical research available on how far these different criteria may have led to discrepancies between the national adjective samples. However, we suspect that the replicability of the Intellect factor depends heavily on the differentiation of dispositions or traits from various other personality characteristics, as realized, for example, in the American and German taxonomies.

Within the category of disposition terms, the German taxonomy gathered temperament and character terms separately from the category of ability terms. ${ }^{3}$ Are abilities and talents therefore overrepresented in the German taxonomy, because the classification discriminated between temperament/character and abilities? First of all, many

\footnotetext{
${ }^{2}$ The nature criterion instructed judges to indicate whether an adjective would fit in the sentence ' $\mathrm{He}$ (She) is [adjective] by nature'. According to the person criterion, judges indicated whether an adjective could be used in answering the question 'Mr (Mrs) $X$ what kind of person is he (she)?' The fundamentality criterion contained the instruction to rate the degree to which each adjective could be seen as a descriptor of a fundamental personality characteristic.

${ }^{3}$ The detailed descriptions of the German category system presented to the judges are 18 pages long. They are available from the authors (in German). For the category of disposition terms, the German raters were told to select those terms that described behaviours that they considered to be stable over time, founded on the individual (internal), and that a target person would exhibit consistently across various situations. Using their competence as native speakers, raters had to judge whether such adjectives could be used for a general description of a person in sentences such as 'The target person is ....', 'The target person is a ... type.' After assigning an adjective to the disposition category, raters had to decide whether the adjective in question indicated a disposition that referred to an ability, a talent, or a shortcoming or even lack of an ability/talent. If this was not the case, the adjective was assigned automatically to the category of temperament and disposition terms.
} 
abilities and talents must be among the most stable dispositions that exist, and hardly any author would question their classification as dispositions. Therefore, prototypical ability terms are probably also particularly relevant for describing persons-a criterion that may come close to the Dutch selection criteria-and are at least no less relevant than prototypical temperament and character descriptors. In our taxonomy, 10 experts gave an average rating of 2.97 on a three-point scale assessing the relevance to personality of the prototypical temperament and character terms (terms that were classified as such by the majority of raters). This did not differ from the mean relevance to personality of the prototypical ability terms $(M=2.97, t(428)=0.82)$. When it is also considered that the raters first classified an adjective as a disposition term and only then decided whether it belonged to the class of ability terms, we can find little support for the assumption that the "German fifth factor can be understood as a more or less direct result of the inclusion of the category "Abilities, talents, or their absence" to the German trait inventory' (De Raad, 1994), or that 'the Germanic acknowledgement of the fifth factor as Intellect is partially to be ascribed to a biased variable selection' (De Raad, 1994). It is far more the case that the fifth factor found in our taxonomy shows a high level of agreement with the fifth factor in Goldberg's taxonomy, whose core is defined essentially by the features 'intellect', 'aesthetics', and 'creativity' (Hofstee, De Raad and Goldberg, 1992; Hofstee et al., 1992).

\section{RELATIONS BETWEEN DISPOSITIONS AND VALUES}

The differentiation between dispositions and values (attitudes, opinions, beliefs) in the German taxonomy is based essentially on the work of Guilford (1959) and the taxonomy of Wiggins (1979). The value category covers terms describing the values, principles, and norms acquired during the process of socialization. Many of these 'attitudes' have a thoroughly habitual character, and have therefore been labelled as traits by other researchers (see the facet Values of the NEO model; Costa and McCrae, 1985). However, if one tends to view attitudes more as action prescriptions or behavioural intentions, then it would seem possible to discriminate them from temperament and character traits. We considered this to be a meaningful step, because we wanted to compile the most differentiated taxonomy of individual differences possible. Tests on the classifications showed that a reliable discrimination was possible between this category and the other categories in the taxonomy (see Angleitner et al., 1990). As the German FFM is exclusively based on temperament, character, and ability terms, the inclusion of terms from the category 'Attitudes and Worldviews' would probably have decisive consequences for the meaning of the fifth factor. Thus, the selection of disposition terms contains only a few adjectives associated with the facet of Openness to Values, and these load primarily on Factor II (Agreeableness, e.g., tolerant, open-minded). If general values constitute a central aspect of the fifth factor, then the inclusion of attitude and value terms should particularly change the meaning of the fifth factor. On the other hand, the work of Johnson (1994) and Trapnell (1994) suggests that this would change the meaning of the third factor (Conscientiousness) as well. One can obtain a rough idea of the impact of the inclusion of attitude and value terms on the German FFM by inspecting Table 1. This table presents correlations between the five German factors (based on a selection of 430 
prototypical disposition terms) and a selection of adjectives describing attitudes and values that were not included in the sample of 430 disposition terms.

Table 1. Correlations among Big-Five factor scores derived from a principal component analysis of 430 adjective-rating scales and selected adjectives describing attitudes and world views

\begin{tabular}{lrrrrr}
\hline Factors & \multicolumn{1}{c}{ I } & \multicolumn{1}{c}{ II } & \multicolumn{1}{c}{ III } & \multicolumn{1}{c}{ IV } & \multicolumn{1}{c}{ V } \\
\hline Conventional & $\mathbf{- 0 . 2 2}$ & 0.06 & $\mathbf{0 . 3 1}$ & 0.06 & $-\mathbf{0 . 2 6}$ \\
Conservative & $-\mathbf{0 . 2 5}$ & $-\mathbf{0 . 0 5}$ & $\mathbf{0 . 3 1}$ & 0.08 & $\mathbf{- 0 . 2 4}$ \\
Traditional & $-\mathbf{0 . 2 5}$ & -0.00 & $\mathbf{0 . 3 1}$ & 0.10 & $-\mathbf{0 . 1 7}$ \\
Untraditional & $\mathbf{0 . 2 1}$ & $\mathbf{0 . 0 6}$ & -0.00 & 0.02 & $\mathbf{0 . 2 8}$ \\
Idealistic & 0.02 & 0.18 & -0.04 & -0.08 & $\mathbf{0 . 2 1}$ \\
Liberal & -0.01 & $\mathbf{0 . 2 7}$ & -0.10 & -0.03 & 0.11 \\
Unconventional & $\mathbf{0 . 2 0}$ & 0.10 & $-\mathbf{0 . 2 1}$ & -0.08 & 0.15 \\
Moral & $-\mathbf{0 . 2 4}$ & $\mathbf{0 . 0 0}$ & 0.17 & 0.11 & -0.01 \\
Immoral & $\mathbf{0 . 2 5}$ & $-\mathbf{0 . 1 3}$ & $\mathbf{- 0 . 2 9}$ & -0.12 & $-\mathbf{0 . 1 6}$ \\
\hline
\end{tabular}

Note: The five factor labels are as follows: Extraversion (I), Agreeableness (II), Conscientiousness (III), Emotional Stability (IV), and Intellect (V).

It can be seen that the inclusion of attitudes and values would probably alter the meaning of not only Factor V and III but also of Factor I (Extraversion). If the attitudes and values in Table 1 are accepted as indicators of the facet Openness to Values, this facet is not an exclusive characteristic of the fifth factor.

\section{WHAT IS THE CORE OF THE FIFTH FACTOR?}

In searching for an answer to this question, one stumbles over similar problems to those that arise when one tries to discriminate between intelligence and creativity. Research in both these fields has widely accepted a threshold model proposed by Guilford (1967), in which intelligence is viewed as a necessary but not a sufficient condition of creativity. Is Intellect (Openness to Ideas) perhaps a necessary but not a sufficient condition for many peripheral features of Openness (values, actions, feelings)?

Johnson (1994) and Saucier (1992; 1994) have presented several plausible arguments as well as empirical findings in support of the assumption that the facets Ideas and Aesthetics in the NEO model form the core of the fifth factor. Factor analyses of the German version of the NEO-PI-R have also provided corresponding results (Ostendorf and Angleitner, 1994). Two principal component analyses $(N=$ 1324 self-ratings and $N=207$ peer ratings) of the NEO-PI-R facets resulted in a FFM in which the fifth factor was loaded most highly by the facets Ideas $(0.70$ (self), 0.73 (peer) and Aesthetics (0.73 (self), 0.75 (peer)). The other facets showed loadings in the self-rating domain ranging from 0.51 (Actions) to 0.63 (Fantasy). In the peer-rating domain loadings ranged from 0.62 (Values) to 0.67 (Feelings). Analogously to Johnson's (1994) findings the AB5C analysis of the scales showed 
that the Openness facets of the NEO-PI-R were primarily associated with features of Factors I+ and III-. However, the conclusion that the core of Factor $\mathrm{V}$ is Imagination (Saucier, 1992; 1994) or Creative Mentality (Johnson, 1994) was frequently based on analyses of scales that had been derived deductively in order to measure the five factors. These scales were generally employed in highly selective samples (college students or interested participants who probably scored particularly highly on Openness to Ideas). However, Brand (1994) has pointed out that such a restriction of range may well lead to a clear underestimation of the importance of the Ideas facet. In less strongly biased samples, we find, for example, that correlations between a teacher's ratings of the intelligence of students and the students' actual IQ measured with the Wechsler Intelligence Scales are around 0.80 (Brickenkamp, 1975). That intelligence is a feature of particular social importance is indicated, for example (i) by its strong association with evaluation; (ii) by the fact that it can be deduced with high validity even from minimal contacts by strangers (Borkenau and Liebler, 1992; 1993); and (iii) by the fact that the language of personality provides a very comprehensive vocabulary to describe this trait.

Thus, there are some important reasons why the Ideas facet could belong to the core of the fifth factor. This does not imply that other more subtle individual differences are not associated with Factor V, but these are apparently not important enough to be addressed by ordinary people and entered into their personality language. Our analysis of a representative set of German disposition adjectives provided a clear FFM in which the fifth factor was marked by variables that could be assigned primarily to the facet Openness to Ideas and secondarily to the facets Aesthetics and Fantasy (Angleitner and Ostendorf, 1992). A subsequent AB5C analysis showed not only similarities but also discrepancies with the results reported by Johnson (1994): similarities were that the majority of adjectives with primary loadings on Factor V marked the AB5C factors V+V+ (16 terms), V + IV + (17 terms), V + III + (15 terms), V+III - ( 9 terms), and V+I+ (16 terms). In this way, the secondary meanings of the Factor $\mathrm{V}$ variables in this study could be described appropriately with the labels Surgent Mentality, Constrained Mentality, and Unconstrained Mentality proposed by Johnson (1994). The main difference with Johnson's results (1994) was that the Factor $\mathrm{V}+\mathrm{V}+$ was marked exclusively by features of the Ideas facet (e.g. intelligent, ingenious, clever, talented, gifted, educated). Thus is was not labelled Creative Mentality, but could be described more adequately as an Intellect factor. The variables that loaded on Factor $\mathrm{V}+\mathrm{I}+$ (e.g. scintillatingly witty, expressive, verbally fluent) showed that this factor could be interpreted in terms of Surgent Mentality. Nonetheless, features of Openness to Feelings and Actions-as could be expected according to Johnson - did not belong to the content measured by Factor $\mathrm{V}+\mathrm{I}+$. Rather, the factor was associated with aspects of Openness to Fantasy (full of ideas, creative). Constrained Mentality $(\mathrm{V}+\mathrm{III}+)$ described a crystallized form of intellect: Competence (knowledgeable, able, competent, informed). Unconstrained Mentality (V+III - ) corresponded to features of Openness to Aesthetics (e.g. artistic, poetic, musical, tasteful). Further relevant relationships of Factor V variables were also found with the AB5C Factor V+IV+ (e.g. highly educated, sophisticated, wise) measuring aspects of Culture (Norman, 1963). Table 2 presents an overview of the results of Saucier (1992; 1994), Johnson (1994; see also Johnson and Ostendorf, 1993), and results obtained in our own studies. From this table it can be concluded that at least the analyses of Saucier and Johnson are in quite good agreement. 
Table 2. An overview of the results in the studies of Saucier (1992; 1994), Johnson (1994; Johnson and Ostendorf, 1993), and Ostendorf and Angleitner

\begin{tabular}{|c|c|c|c|}
\hline & Saucier & Johnson & Ostendorf and Angleitner \\
\hline $\mathrm{V}+\mathrm{V}+$ & $\begin{array}{l}\text { Imagination } \\
\text { Core of Factor V, common } \\
\text { to Openness (Ideas and } \\
\text { Aesthetics) and Intellect: } \\
\text { creative, original, } \\
\text { imaginative }\end{array}$ & $\begin{array}{l}\text { Creative Mentality } \\
\text { Heart of Factor V, } \\
\text { common to Openness } \\
\text { (Ideas and Aesthetics) and } \\
\text { Intellect: creative, artistic, } \\
\text { imaginative }\end{array}$ & $\begin{array}{l}\text { Intellect (Ideas) } \\
\text { intelligent, ingenious, } \\
\text { clever, talented, gifted }\end{array}$ \\
\hline $\mathrm{V}+\mathrm{III}+$ & $\begin{array}{l}\text { Imagination and } \\
\text { Organization } \\
\text { Component of Intellect }\end{array}$ & $\begin{array}{l}\text { Constrained Mentality } \\
\text { Controlled Intellect: } \\
\text { intelligent, broad interests, } \\
\text { cultured }\end{array}$ & $\begin{array}{l}\text { Constrained Mentality, } \\
\text { Competence } \\
\text { knowledgeable, able, } \\
\text { competent, informed }\end{array}$ \\
\hline $\mathrm{V}+\mathrm{III}-$ & $\begin{array}{l}\text { Unconventionality } \\
\text { Component of Openness }\end{array}$ & $\begin{array}{l}\text { Unconstrained Mentality } \\
\text { Component of Openness } \\
\text { (Fantasy and Values); } \\
\text { impulsive version of Factor } \\
\text { V: changeable, unorthodox }\end{array}$ & $\begin{array}{l}\text { Unconstrained Mentality } \\
\text { (Aesthetics) } \\
\text { artistic, poetic, musical, } \\
\text { tasteful }\end{array}$ \\
\hline $\mathrm{V}+\mathrm{II}+$ & $\begin{array}{l}\text { Component of Openness: } \\
\text { Sensitivity, Empathy }\end{array}$ & & \\
\hline V + IV + & $\begin{array}{l}\text { Detachment from Emotions } \\
\text { Component of Intellect }\end{array}$ & & $\begin{array}{l}\text { Wisdom, Culture } \\
\text { highly educated, } \\
\text { sophisticated, wise, } \\
\text { cultured }\end{array}$ \\
\hline $\mathrm{V}+\mathrm{IV}-$ & $\begin{array}{l}\text { Component of Openness } \\
\text { (Feelings and Unproductive } \\
\text { Fantasy) }\end{array}$ & & \\
\hline $\mathrm{V}+\mathrm{I}+$ & & $\begin{array}{l}\text { Surgent Mentality } \\
\text { Component of Openness } \\
\text { (Feelings and Actions); } \\
\text { impulsive version of Factor } \\
\text { V; Expressive Intellect: } \\
\text { experimenting, original, } \\
\text { prefer variety, independent, } \\
\text { liberal, untraditional, } \\
\text { sophisticated }\end{array}$ & $\begin{array}{l}\text { Surgent Mentality } \\
\text { (Creativity) } \\
\text { scintillatingly witty, } \\
\text { expressive, verbally fluent, } \\
\text { full of ideas, creative }\end{array}$ \\
\hline
\end{tabular}

\section{CONCLUSIONS}

The meaning of Factor V (and of the other factors) depends strongly on the sample of variables studied. If we want to clarify its 'true' meaning, it is not sufficient to use small samples of items to construct large numbers of specific, idiosyncratic scales and then to correlate these with various versions of the fifth factor. Although more precise information on the meaning of this factor may be obtained from factor analyses of comprehensive item pools, even then, item selection will still depend on the definition of personality (De Raad, 1994). However, the central components 
of the factor will probably appear across all different versions of the factor, provided that they are based on large samples of items measuring dispositions. Researchers who want to proceed from a conception of Factor $V$ in which different measures intersect or converge should therefore follow Johnson's (1994) proposal and base their concepts on the traits Intellect and Creativity.

Other researchers who prefer competition may like to take an idiosyncratic position or may incorporate a large range of non-dispositional variables into the five-factor structure in case these variables correlate with one or more factors of the Big Five. However, including many variables that do not refer to dispositions in the model will most probably change the original five-factor structure. In fact, three very different dimensions are quite sufficient to describe the locations of persons and objects in semantic space when descriptors are selected from the entire lexicon and not just the personality lexicon (Osgood, 1962). Finally, only studies on the external validity of the various versions of Factor $V$ can help to decide which facets of the factor are most important in terms of predicting significant life criteria.

\section{REFERENCES}

Allport, G. W. and Odbert, H. S. (1936). 'Trait names: a psycholexical study', Psychological Monographs, 47: No. 211.

Angleitner, A. and Ostendorf, F. (1992). 'Towards a taxonomy of personality descriptors', paper presented at the symposium 'Advances in Personality', 25th International Congress of Psychology, Brussels, July 19-24, 1992.

Angleitner, A., Ostendorf, F. and John, O. P. (1990). 'Towards a taxonomy of personality descriptors in German: a psycho-lexical study', European Journal of Personality, 4: 89-118.

Borkenau, P. and Liebler, A. (1992). 'Trait inferences: sources of validity at zero acquaintance', Journal of Personality and Social Psychology, 62: 645-657.

Borkenau, P. and Liebler, A. (1993). 'Convergence of stranger ratings of personality and intelligence with self-ratings, partner-ratings, and measured intelligence', Journal of Personality and Social Psychology, 65: 546-553.

Brand, C. (1994). Open to Experience-Closed to Intelligence: why the 'Big Five' need to be converted back into the 'Capacious Six'. European Journal of Personality, 8: 299-310.

Brickenkamp, R. (1975). Handbuch psychologischer und pädagogischer Tests. [Handbook of Psychological and Educational Tests], Hogrefe, Göttingen.

Brokken, F. B. (1978). The Language of Personality, Krips, Meppel.

Caprara, G. V., Barbaranelli, C., Borgogni, L. and Perugini, M. (1993). 'The Big Five Questionnaire: a new questionnaire to assess the Five Factor Model', Personality and Individual Differences, 15: 281-288.

Caprara, G. V. and Perugini, M. (1994). 'Personality described by adjectives: generalizability of the Big Five to the Italian lexical context', European Journal of Personality, 8: in press.

Costa, P. T., Jr. and McCrae, R. R. (1985). The NEO Personality Inventory Manual, Form S and Form R, Psychological Assessment Resources, Odessa, FL.

De Raad, B. (1992). 'The replicability of the Big Five personality dimensions in three wordclasses of the Dutch language', European Journal of Personality, 6: 15-29.

De Raad, B. (1994). 'An expedition in search of a fifth universal factor; key issues in the lexical approach', European Journal of Personality, 8: 229-250.

Goldberg, L. R. (1990). 'An alternative "description of personality": the Big-Five factor structure', Journal of Personality and Social Psychology, 59: 1216-1229.

Goldberg, L. R. (1992). 'The development of markers for the Big-Five factor structure', Psychological Assessment, 4: 26-42.

Guilford, J. P. (1959). Personality, McGraw-Hill, New York, NY.

Guilford, J. P. (1967). The Nature of Human Intelligence, McGraw-Hill, New York, NY.

Hofstee, W. K. B., De Raad, B. and Goldberg, L. R. (1992). 'Integration of the Big Five 
and Circumplex approaches to trait structure', Journal of Personality and Social Psychology, 63: $146-163$.

Hofstee, W. K. B., De Raad, B., Kiers, H. A. L., Ostendorf, F. and Goldberg, L. R. (1992). 'Dutch-American-German comparison of the ABSC trait taxonomy', paper presented at the Sixth Conference of the European Association of Personality Psychology, Groningen, June 15-19, 1992.

Johnson, J. A. (1994). 'Clarification of Factor Five with the help of the AB5C model', European Journal of Personality, 8: 311-334.

Johnson, J. A. and Ostendorf, F. (1993). 'Clarification of the Five Factor Model with the Abridged Big Five dimensional Circumplex', Journal of Personality and Social Psychology, 65: $563-576$.

Norman, W. T. (1963). 'Toward an adequate taxonomy of personality attributes: replicated factor structure in peer nomination personality ratings', Journal of Abnormal and Social Psychology, 66: $574-583$.

Norman, W. T. (1967). '2800 personality trait descriptors: normative operating characteristics for a university population', Department of Psychology, University of Michigan.

Osgood, C. E. (1962). 'Studies on the generality of affective meaning systems', American Psychologist, 17: 10-28.

Ostendorf, F. (1990). Sprache und Persönlichkeitsstruktur: Zur Validität des Fünf-FaktorenModells der Persönlickeit [Language and Personality Structure: Towards the Validity of the Five-Factor Model of Personality], Roderer, Regensburg.

Ostendorf, F. and Angleitner, A. (1992). 'On the generality of comprehensiveness of the fivefactor model of personality: evidence for five robust factors in questionnaire data'. In: Caprara, G. V. and Van Heck, G. L. (Eds), Modern Personality Psychology: Critical Reviews and New Directions, pp. 73-109. Harvester-Wheatsheaf, New York, NY.

Ostendorf, F. and Angeitner, A. (1993). 'A German replication study of the Five-Factor-Model based on a comprehensive taxonomy of personality descriptive adjectives', paper presented at the Sixth Meeting of the International Society for the Study of Individual Differences, Baltimore, MD, July 17-21, 1993.

Ostendorf, F. and Angleitner, A. (1994). 'Psychometric properties of the German translation of the NEO Personality Inventory (NEO-PI-R)', unpublished manuscript, University of Koblenz-Landau.

Saucier, G. (1992). 'Openness versus Intellect: much ado about nothing?', European Journal of Personality, 6: 381-386.

Saucier, G. (1994). 'Trapnell versus the lexical factor: more ado about nothing?' European Journal of Personality, 8: 291-298.

Szirmák, Z. and De Raad, B. (1994). 'Taxonomy and structure of Hungarian personality traits', European Journal of Personality, 8: 95-117.

Trapnell, P. D. (1994). 'Openness versus Intellect: a lexical left turn', European Journal of Personality, 8: 273-290.

Wiggins, J. S. (1979). 'A psychological taxonomy of trait-descriptive terms: the interpersonal domain', Journal of Personality and Social Psychology, 37: 395-412. 